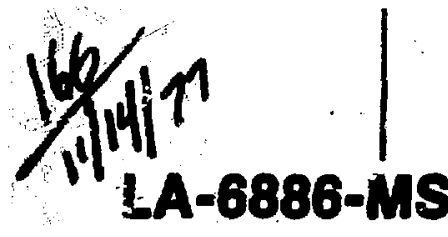

Informal Report

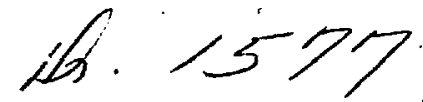

uc-33

Issued: October 1977

\title{
Statistical Analysis and Planning of Multihundred-Watt Impact Tests
}

\author{
H. F. Martz, Jr.*
}

M. S. Waterman

-Visiting Staff Member. Department of Mechanical and Industrial Engineering, University of Utah, Salt Lake City, UT 841 10. 
This work was supported by the US Energy Research and Development Administration, Division of Nuclear Ressarch and Arplications.

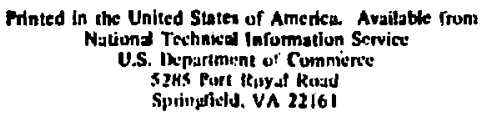

\begin{tabular}{|c|c|c|c|c|c|c|c|}
\hline $\begin{array}{l}\text { Wierolicts } \\
001-025 \\
\text { (126-050 } \\
051-075 \\
(176-161) \\
101-125\end{array}$ & $\begin{array}{r}3.00 \\
4.00 \\
4.50 \\
5.25 \\
6.00 \\
6.50\end{array}$ & $\begin{array}{l}126-150 \\
151-175 \\
176-200 \\
201-225 \\
226-250\end{array}$ & $\begin{array}{l}7.25 \\
6.100 \\
9.001 \\
9.25 \\
4.511\end{array}$ & $\begin{array}{l}251-275 \\
276.300 \\
301-325 \\
326-350 \\
351.375\end{array}$ & $\begin{array}{l}10.75 \\
11.00 \\
11.75 \\
12.00 \\
12.50\end{array}$ & $\begin{array}{r}376-400 \\
401+25 \\
426-450 \\
451-475 \\
476-91,1\end{array}$ & $\begin{array}{l}13.00 \\
13.25 \\
14.00 \\
14.50 \\
15.110\end{array}$ \\
\hline \multicolumn{8}{|c|}{ 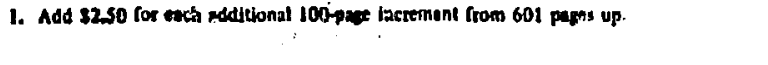 } \\
\hline \multicolumn{8}{|c|}{ 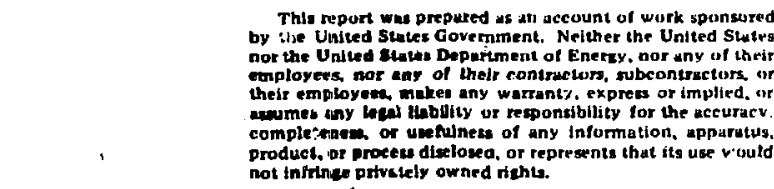 } \\
\hline
\end{tabular}


CONTENTS

I. INTRODUCTION AND PURPOSE $\ldots \ldots \ldots \ldots \ldots \ldots \ldots \ldots \ldots \ldots \ldots \ldots \ldots \ldots \ldots \ldots \ldots \ldots \ldots \ldots$

II SOME POSSIBLE STATISTICAL IMPACT TEST DATA ANALYSIS MODELS. ......... 2

III. STATISTICAL ANALYSIS OF MHR IMPACT TEST RESULTS $\ldots \ldots \ldots \ldots \ldots \ldots \ldots \ldots \ldots \ldots .2$

IV. STATISTICAL PLANNING OF MHW IMPACT TESTS $\ldots \ldots \ldots \ldots \ldots \ldots \ldots \ldots \ldots \ldots \ldots$

v. concLUSIONS $\ldots \ldots \ldots \ldots \ldots \ldots \ldots \ldots \ldots \ldots \ldots \ldots \ldots \ldots \ldots \ldots \ldots \ldots \ldots \ldots \ldots \ldots \ldots \ldots \ldots$

REFERENCES $\ldots \ldots \ldots \ldots \ldots \ldots \ldots \ldots \ldots \ldots \ldots \ldots \ldots \ldots \ldots \ldots \ldots \ldots \ldots \ldots \ldots \ldots \ldots \ldots \ldots \ldots \ldots$

This repart was preportd a an account s" ik oponsored by the United Sutes Govemment .... et the Inited Sutes nor the United Sintes $D^{\circ}$.sument of Esmry, nor any of thels employees, nor any of their conticttors, subcontracton, or thelt emiployees, makes

any wirranty, express or implied, or aseumes any leal

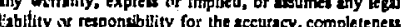

precters

proces dis

process din ssed, of represents that its ux would not
infinge printely owaed nightw. 


\title{
STATISTICAL ANALYSIS AND PLANNING OF MULTIHUNDRED-WATT IMPACT TESTS
}

by

H. F. Martz, Jr.

M. S. Waterman

\begin{abstract}
ABSTRAC̄T
Modular multihundred-watt (MHW) radioisotope thermoelectric generators (RTG's) are used as a power source for spacecraft. Due to possible environmentai contamination. by radioactive materials, numerous tests are required to determine and verify the safety of the RTG. There are results available from 27 fueled MW impact tests regarding hoop failure, fingerprint failure, and fuel failure.

In this report, the data from $t \mathrm{tl} 327$ tests are statistically analyzed for relationships that exist between the test design variables and the failure types. Next, these relationships are used to develop a statistical procedure for planning and conducting either future MWW impact tests or similar tests on other RTG fuel sources. Finally, some conclusions are given.
\end{abstract}

\section{INTRODUCTION AND PURPOSE}

The modular multihundred-watt (MHW) radioisotop thermoelectric genorator (RTG) is a power source for spacecraft. Because of increased concern over possible environmental contamination by radioactive material, numerous tests are required to determine and verify the safety of the RTG. Cramer (1975) reported the results of a Safety Sequential Test (SST) which was designed to investigate the ability of prototype fueled-sphere assemblies (FSA's) to contain their plutonia fuel during a simulated orbital abort resulting in atmospheric reentry and earth impact. The Los Alamos Scientific Laboratory (LASL) evaluated the response of FSA's in the orbital phase. As part of the SST program, several FSA's were impacted onto a granite target by means of a gas gun available at LASL. The impact velocity was controlied according to test specifications. Each FSA was also subjected to a reentry t'sermal pulse to simulate reentry temperature. In addition, the orientation of the cap of the graphite impact shell (GIS), erclosing the postimpact containinent shell (PICS) surrounding the plutonia, was set for each test. These three test design variables will be hence- 
forth referred to as velocity (in $\mathrm{m} / \mathrm{s}$ ), temperature (in ${ }^{\circ} \mathrm{C}$ ), and GIS orientation (in degrees), respectively,

In addition to the FSA's impacted during the SST program, Cramer (1976) reports the impact test results of several FSA's impacted as part of the Safety Verification Test (SVT). This test considered the proofing of flightqualified assemblies, which differed somewhat from those FSA's used in the ȘST program.

Table I summarizes the results of $2 \%$ fueled MW impact tests that have been conducted as of March 1977. The responses of interest are the presence (or absence) of the three failure types (or modes) designated in Table I as hoop failure, fingerprint failure, and fuel failure. An " $x$ " indicates the observed presence, while a "--" indicates the absence, of a failure type.

The purpose of this report is twofold. First, we shall statistically analyze the data in Table I regarding the relationships that exist between the test design variables and the failure types. This will be done in Section III. The second purpose is to utilize the statistical relationships in devaloping a statistical procedure for planning and conducting either future MiW impact tests or similar tests on other RTG fuel sources. This is considered in Section IV. Finally; some conclusions are presented in Section V.

\section{Ii. SOME POSSIBLE STATISTICAL IMPACT TEST DATA ANALYSIS MODELS}

There are several possible statistical models and approaches that can be used to analyze the data in Table I. We review some of these and discuss some of the advantages and disadvantages of each model.

One approach is to use what is known statistically as zero-one linear regression analysis. This technique is discussed by Neter and Wasserman (1974), pp. 320-328. The main advantage of this approach is its ease of application. A disadvantage lies in the fact that probabilities estimated fron the models may be outside the range 0 to 1 . Another ilsadvantage is that such linear models may only represent a first-level approximation to the exact relationships implied by the data.

Another approach is to describe the data by means of suitable logistic response functions. This approach is al so described in Neter and Wasserman (1974), pp. 329-334, as well as by Finney (1952), pp. 454-456. The main advantage of this approach is that it provides a curvilinear response function that is S-shared for the probability of the absence of a failure type. The main disadvantage of this approach is the relative complexity in fitting such curves to the data. In most cases, nonlinear curve fitting procedures must be used, and the entire process becomes somewhat complicated.

A third approach is to use probit analysis. This is also discusser, by Finney (1952). The primary advantage of this approach is that the fitced curves have the s-shaped property. The main disadvantage is the difficulty in using this approach when there is only a single data point observed for a given set of test conditions. Since this is the case for some of the tests in Table $I$, this approach could not be used here.

\section{STATISTICAL ANALYSIS OF MHW IMPACT TEST RESULTS}

Out of the 27 tests sumnarized in Table $\dot{I}, 37 \%$ of the test units experienced a hoop failure; 44\% experienced a fingerprint failure; and 48\% experienced a fucel. 
TABLE I

LASL FUELED MHW IMPACT TEST SUMMARY

\begin{tabular}{|c|c|c|c|c|c|c|c|c|c|c|}
\hline Sample No. & $\begin{array}{l}\text { Volocity } \\
\text { (ats) }\end{array}$ & $\begin{array}{l}\text { Temp. } \\
\left({ }^{\circ} \mathrm{C}\right)\end{array}$ & $\begin{array}{c}\text { GIS } \\
\text { Oriclitation }\end{array}$ & $\frac{\text { Postimpnc }}{\text { Height (cta) }}$ & $\frac{\text { Dimensiuns }}{\text { Mian }(\mathrm{cm})}$ & Hop Straln & 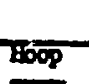 & $\begin{array}{l}\text { Equlure Tyne } \\
\text { Eugerprint }\end{array}$ & $\ln$ & Indavivet \\
\hline AHFT-2 & B3.5 & 1374 & $180^{\circ}$ & 0.48 & $0.67 / 10.68$ & 0.065 & & vio fallum & & 4A, 4 \\
\hline MAT-3 & 84.1 & 1365.5 & $180^{\circ}$ & 0.41 & $0.70 / 0.73$ & 0.134 & $x$ & $\therefore$ & $-\infty$ & 5,5 \\
\hline MIIT-4 & 85.11 & 1375 & $180^{\circ}$ & 0.45 & $0.67 / 0.69$ & 0.081 & $\mathbf{x}$ & $x$ & $\cdots$ & 5,4 \\
\hline MIFT-12 & 87.2 & R. $1480^{\mathrm{a}}$ & $180^{\circ}$ & 0.17 & 0.69 & 0.088 & $x$ & $-\infty$ & $\because$ & $15 B, 23$ \\
\hline NHFT-26 & 75.3 & $R, 1550$ & $70^{\circ}$ & 0.44 & $0.72 / 0.73$ & 0.247 & - & $x$ & - & 51,50 \\
\hline MAIFT-27 & 75.9 & $R, 1550$ & $180^{\circ}$ & $0.5 n$ & $0.05 / 0.60$ & 0.045 & $\infty$ & $\cdots$ & $\mathbf{x}$ & $-\infty$ \\
\hline MTT-29 & 77.1 & 1013.3 & $180^{\circ}$ & 0.46 & $0.66 / 0.68$ & 0.059 & $x$ & $x$ & $x$ & 51 . 52 \\
\hline MITT-30 & 76.2 & $R, \quad 15.50$ & $180^{\circ}$ & 0.18 & $0.65 / 0.66$ & 0.045 & $-\infty$ & $x$ & $-\infty$ & 51,52 \\
\hline$M I F-31$ & 74.1 & R. 1550 & $180^{\circ}$ & 0.18 & $0.65 / 0.67$ & 0.039 & I & $\infty$ & $\mathbf{x}$ & 44,44 \\
\hline 1917-32 & 86.9 & 1370 & $.180^{\circ}$ & 0.46 & $0.67 / 0.199$ & 0.075 & & No Exiluro & & EI-III \\
\hline MET-33 & $\therefore \rightarrow 86.0$ & 1570 & $18 n^{\circ}$ & 0.45 & $0.67 / 0.68$ & 0.066 & & no Elluro & & EI-III \\
\hline MIITT-34 & y. 86.6 & 1375 & $180^{\circ}$ & 0.46 & $0.65 / 0.68$ & 0.056 & & io Eablure & & $m$ \\
\hline MIFT-35 & 85.6 & 1375 & $180^{\circ}$ & 0.45 & $0.66 / 0.68$ & 0.066 & $-\infty$ & $x$ & $x$ & $\mathbf{m}$ \\
\hline MUT-36 & B5. 3 & 1375 & $135^{n}$ & 0.46 & $0 . \dot{0} 7 / 0.68$ & 0.069 & - & $x$ & $x$ & $n c$ \\
\hline MIFT-39 & $86 . ?$ & R, 1100 & $180^{\circ}$ & 0.48 & $0.66 / 0.68$ & 0.061 & $x$ & - & $x$ & WC, a \\
\hline METT -40 . & 68.3 & $\mathrm{R}, 1440$ & $180^{\circ}$ & 0.49 & $0.65 / 0.60$ & 0.038 & - & $=$ & $x$ & $w, n$ \\
\hline Mill-T-45 & 85.0 & $R, 1,1,10$ & $180^{\circ}$ & 0.14 & $0.67 / 0.70$ & 0.083 & - & $x$ & $x$ & EI-III \\
\hline MIITT-47 & 85.6 & R, 1440 & $180^{n}$ & 0.46 & $0.65 / 0.68$ & 0.073 & - & $-\infty$ & $x$ & WE \\
\hline MYFT-48 & 86.9 & R. 1440 & $745^{\circ}$ & 0.44 & $0.71 / 0.72$ & 0.133 & $x$ & $x$ & $-\infty$ & he \\
\hline MIFT-49 & 87.2 & R, 1100 & $180^{\circ}$ & 0.49 & $0.65 / 0.67$ & 0.051 & $x$ & $x$ & $x$ & VE \\
\hline METT-50 & 85.6 & R, 1140 & $281^{\circ}$ & 0.47 & $0.69 / 0.71$ & 0.116 & - & $x$ & $x$ & EI-III \\
\hline MIt1T-54 & 85.3 & $R, 1440$ & $180^{\circ}$ & 0.45 & $0.69 / 0.70$ & 0.100 & $x$ & $-\infty$ & $x$ & m \\
\hline MIFT-55 & 86.9 & $R, 1440$ & $180^{\circ}$ & 0.46 & $0.68 / 0.70$ & 0.091 & - & $\therefore$ & $x$ & fD \\
\hline MiFT-50 & 86.7 & $R, 1440$ & $180^{\circ}$. & 0.16 & $0.66 / 0.68$ & 0.066 & $x$ & $x$ & - & 5 \\
\hline MFIT-57 & 86.3 & R, 1400 & $180^{\circ}$ & 1.15 & $0.68 / 0.69$ & 0.091 & $\cdots$ & $x$ & 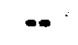 & ID \\
\hline MUT-58 & 85.6 & R, 1 isto & $180^{\circ}$ & 0.47 & $0.68,0.68$ & $0: 081$ & $\cdots$ & $\cdots$ & 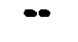 & fil \\
\hline$\frac{\text { MiFT-59 }}{\mathrm{R}: \text { reent }}$ & 86.3 & $R, 1440$ & $180^{\circ}$ & 9.49 & $0.66 / 0.67$ & 0.050 & $\cdots$. & - & $-\infty$ & 80 \\
\hline
\end{tabular}


failure. It is important to consider the relationships between each of these failure types and the velocity, temperature, and GIS orientation used in the tests.

In this section we shall analyze the relationships between each of the three failure types and the test design variables, as implied by the data in Table I. The results will be used in Section IV to determine a statistical testing procedure for use in planning and conducting future MHW or other impact tests.

Due to the ease and simplicity of the zero-cne linear regiession analysis model discussed in Section II, this model will be used here for an analysis of the data in Table I. While other more sophisticated models could be employed (see Section. II), the approach selected for use here is adequate, as will be seen. The model to be used considers a dependent dichotomous random variable $Y$ that can assume only the values " 0 " and " 1 ". The value "0" will be associated with the presence of a failure type under consideration, while tue value "1" will denote the absence of such a failure type. Further, for a certain failure type, let

$$
P\{\text { Failure Type Does Not Occur }\}=P\{Y=1\}=p
$$

and

$\mathrm{P}\{$ Failure Type Does Occur $\}=P\{Y=0\}=1-\mathrm{p}$.

In statistical terminology, $Y$ is said to be a Bernoul? $i$ random variable. We corsider the multiple linear regression of $Y$ on the test design variables. Consider the multiple linear regression model given by

$$
E(Y)=\beta_{0}+\beta_{1} X_{1}+\beta_{2} X_{2}+\beta_{3} X_{3}, Y=0,1
$$

where $E(Y)$ denotes the expected response, and where $x_{1}, X_{2}$, and $x_{3}$ are used tc denote the velocity, temperature, and orientation of the test-failed MHI, respectively. By means of Eqs. (1) and (2), it is easily shown that $E(Y)=p$, and thus the regression model in Eq. (3) may be interpreted as giving the probability that the failure type under consideration does not occur. Further, it is easily shown that the variance of $Y, V(Y)$, is given by

$$
V(Y)=E(Y)[1-E(Y)]=p(1-p),
$$

which is not constant as it must be for use of ordinary least squares methods applied to Eq. (3). This may be corrected by use of so-called "weighted least squares" methods [see Neter and Wasserman (1974)]. The basic procedure followed in obtaining the results given below will now be described. First, ordinary (unweighted) least squares methods were used to fit Eq. (3) for each of the three failure types. The procedure was implemented by means of the SAS code GLM on an 
IBM 370/115 system. The resulting equations are calculated to be

Hoop Failure Type: $\hat{p}_{h}=-1.9364+0.0016 x_{1}+0.0016 x_{2}+0.0008 x_{3}$;

Fingerprint Failure Type:

$$
\hat{\mathrm{p}}_{\mathrm{f}}=-1.9858+0.0023: \mathrm{x}_{1}+0.00089 \mathrm{x}_{2}+0.0065 \mathrm{x}_{3}
$$

and

Fuel Failure Type: $\hat{p}_{f u}=-4.0662+0.0318 x_{1}+0.0014 x_{2}-0.0003 x_{3}$,

where the subscripts $h, f$, and fu denote hoop, fingerprint, and fuel failure types, respectively. This constituted Stage 1 of a two-stage procedure.

The weights to be used in Stage 2 (the weighted least squares portion) are given by the reciprocal of Eq. (4). These weights were estimated as $1 /[\hat{\mathrm{p}}(1-\hat{\mathrm{p}})]$, where $\hat{p}$ was calculated from Eqs. (5) - (7) for each failure type. Secondly, the regression equation (3) was fitted by use of stepwise weighted least squares methods for each of the three failure types. To accomplish this, the BMDP code BMDPZR was used on an IBM $370 / 165$ system. The fitted equations resulting from Stage 2 are

Hoop Failure Type: $\hat{\mathrm{p}}_{\mathrm{h}}=-2.2451+0.0059 \mathrm{X}_{1}+0.0017 \mathrm{X}_{2}+0.0003 \mathrm{X}_{3} ;$

Fingerprint Failure Type:

$$
\hat{p}_{f}=-2.1559+0.0062 x_{1}+0.0008 x_{2}+0.0061 x_{3} ;
$$

and

Fuel Failure Type: $\hat{\mathrm{p}}_{\mathrm{fu}}=-4.0387+0.0322 \mathrm{x}_{1}+0.0014 \mathrm{x}_{2}-0.0004 \mathrm{x}_{3} \cdot$

Table II contains information regarding the quality of fit of Ess. (8), (9), and (10). In all cases, the fit is observed to be adequate, particularly for fingerprint-type failure, which is observed to have the best fit. In Table II, $\mathrm{R}^{<}$denotes the proportion of the observed successes and failures which are accounted for by the test design variables. The Regression F-Values indicate that a slightly significant linear relationship exists between the three failure types and the test design variables. The Standard Error of Estimate values are estimates of the standard deviation of the error in the observed data and the fitted equations. Thus, they are measures of the inherent accuracy of estimates given by the fitted equations.

\begin{tabular}{|c|c|c|c|}
\hline Equation & $R^{2}$ & Regression F-Value & Sčd. Error of Estimate \\
\hline $\begin{array}{r}(8) \\
(9) \\
(10)\end{array}$ & $\begin{array}{l}0.22 \\
0.44 \\
0.27\end{array}$ & $\begin{array}{l}2.117 \\
5.903 \\
2.885\end{array}$ & $\begin{array}{l}0.47 \\
0.40 \\
0.46\end{array}$ \\
\hline
\end{tabular}

TABLE II 
The results of the stepwise analyses indicate that not all of the test design variables are sufficiently correlated with the failure ispes to merit their inclusion in prediction models. Let us now examine the important contributing test design variables in each separate model. First, let us consider hoop failure type. The sirgle most important test design variable for explaining hoop failure was found to be temperature. The simple correlation between t:emperature and hoop failure was found to be $46 \%$. The velocity and orientation are virtually uncorrelated with hoop failure, and together increase the multiple correlation by only $0.5 \%$. The final prediction model for the probability that a hoop failure typo does not occur is given by

$$
\text { Hoop Failure Type:" } \hat{\mathrm{p}}_{\mathrm{h}}=-1.6121+0.0016 \text { (temperature) }
$$

It is observed that the probability that a hoop failure does not occur increases rough $1 y \quad 0.16 \%$ for each degree rise in temperature between 1 ng $3^{\circ} \mathrm{C}$ and $1550^{\circ} \mathrm{C}$. Thus, a $500^{\circ} \mathrm{C}$ increase in temperature from $1050^{\circ} \mathrm{C}$ to $1550^{\circ} \mathrm{C}$ raises the estimated probability that a hoop failure does not occur from roughly $7 \%$ to $87 \%$. Now consider the fingerprint failure type. The single most important test design variable was found to be the GIS orientation of the test unit. This variable was observed to have a simple correlation of $64 \%$ with fingerprint failure, while both velocity and temperature had insignificant correlations. Together, velocity and temperature increased the multiple correlation by only 2.02\%. The final prediction model for the probability that a fingerprint failure type does not occur is given by

Fin rprint Failure Type: $\hat{p}_{f}=-0.3653+0.0056$ (GIS Orientation).

It is observed that the probability that a fingerprint failure does not occur increases roughly $0.56 \%$ of each degree change in the GIS orientation. Thus, changing the GIS orientation from approximately $70^{\circ}$ to $180^{\circ}$ raises the estimated probability that a fingerprint failure does not occur from roughly $3 \%$ to $64 \%$.

Finally, let us consider the fuel failure type. The single most inportant test design variable is temperature; however, velocity also plays a significant role in explaining the fuel failure type. Together, both of these test design variables have a multiple correlation of $52 \%$ with fuel failure type, with temperature curtrijuting $35 \%$ and velocity contributing the remaining $17 \%$. The GIS orientation is virtually uncorrelated with this failure type and increases the multiple correlation by only 0.07\%. The final prediction model for the probability that a fuel failure type does not occur is given by

Fuel Failure Type:

$$
\hat{p}_{f u}=-4.1496+0.0325 \text { (velocity) }+0.0014 \text { (temperature) }
$$

It is observed that the probability that a fuel failure type does not occur increases roughly $1.13 \%$ for each simultaneous single-degree rise in temperature and 0.3 meter per second increase in velocity. Simultaneously increasing the 
temperature from $1100^{\circ}$ to $1550^{\circ} \mathrm{C}$ and increasing the velocity from $68.6 \mathrm{~m} / \mathrm{s}$ to 86.9 $\mathrm{m} / \mathrm{s}$ is expected to raise the estinated probability that a fuel failure does not occur from roughly $0-84 \%$. If temperature is held fixed, then increasing the velocity from $68.6 \mathrm{~m} / \mathrm{s}$ to $86.9 \mathrm{~m} / \mathrm{s}$ raises the probability by roughly $59 \%$. On the other hand, if velocity is held fixed, then increasing the temperature from $1100^{\circ} \mathrm{C}$ to $1550^{\circ} \mathrm{C}$ raises the probability that a fuel failure does not occur by approximately $63 \%$.

Table III contains information regarding the quality of fit of Eqs. (11) (13). By comparing Tables II and III, it is observed that the fit of Eqs. (11) (13) is nearly as good as the fit of Eqs. (8) - (10), respectively. Thus, Eqs. (11) - (13) will be considered in the next section.

Finally, lei us illustrate the use of Eqs. (11) - (13). At the test design levels used for MHFT-59 in Table I $\left(86.26 \mathrm{~m} / \mathrm{s}, 1440^{\circ} \mathrm{C}, 180^{\circ}\right)$, the estimated probabilities of not observing a hoop : fingerprint, or fuel failure type are $69 \%$, $64 \%$, and $67 \%$, respectively. From Tabie $I$, it is observed that no failures occurred for this test unit.

\section{STATISTICAL PLANNING MHW IMPACT TESTS}

The prediction models developed and discussed is the preceding section will now be used to determine which combinations of test design variables to use in planning and conducting future $\mathrm{MHW}$ impact tests. These results can be extrapolated to other impact test programs; however, only MHW impact test planning will be considered here.

First, consider hoop failure type. Based on Eq. (11), Fig. 1 graphically provides the required test temperature that is expected to yield a corresponding estimated probability $\hat{p}_{h}$ that a hoop failure type does not occur. For example, if $\hat{\mathrm{p}}_{\mathrm{h}}=0.75$ is desired, then a temperature of $1476^{\circ} \mathrm{C}$ should be used in conducting the test. The break-even temperature for which there is a $50 / 50$ chance that a hoop failure type does not occur is seen to be $1320^{\circ} \mathrm{C}$. The mean temperature used in the 27 tests in Table $\mathrm{I}$ is $1398.2^{\circ} \mathrm{C}$, which corresponds to an estimated probability of $63 \%$ that a hoop failure type will not occur. This corresponds to the $63 \%$ observed proportion of test units that did not experience a hoop failure.

Now let us consider fingerprint failure type. Based on Eq. (12), Fig. 2 graphically provides the required test GIS orientation that is expected to yield a corresponding estimated probability $\hat{p}_{f}$ that a fingerprint failure type does not occur. alle inset in Fig. 2 gives the estimated probability $\hat{p}_{f}$ corresponding to the previous test GIS orientations of $45^{\circ}, 70^{\circ}, 80^{\circ}, 135^{\circ}$, and $180^{\circ}$. If, for example, $\hat{\mathrm{p}}_{f}=0.75$ is desired, then a GIS orientation of $180^{\circ}$ should be used in conducting the test. It is noted that $180^{\circ}$ is used when $\hat{p}_{f}$ equals or exceeds

TABLE III.

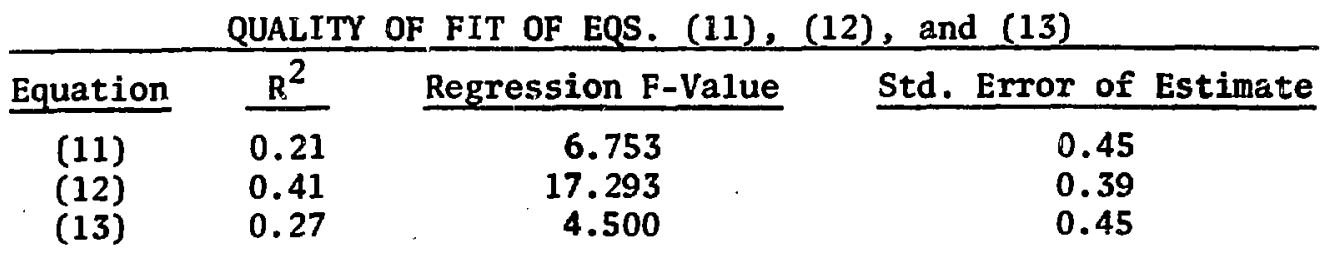




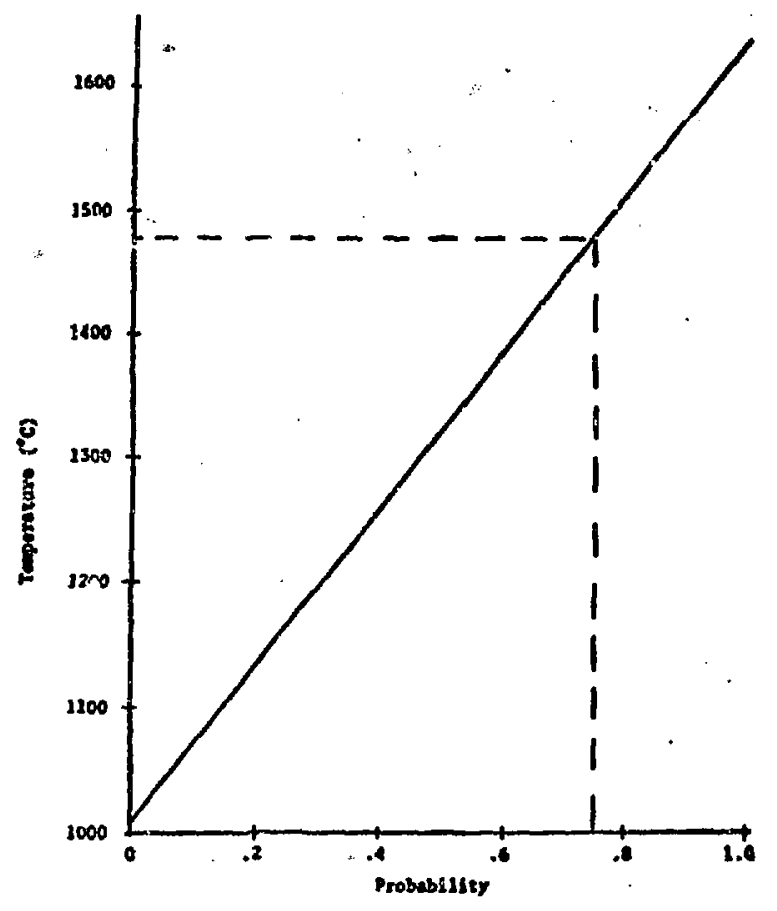

Fig. 1 .

Requirad test temperature as a function of the desired probability that a hoop failure type does not occur.

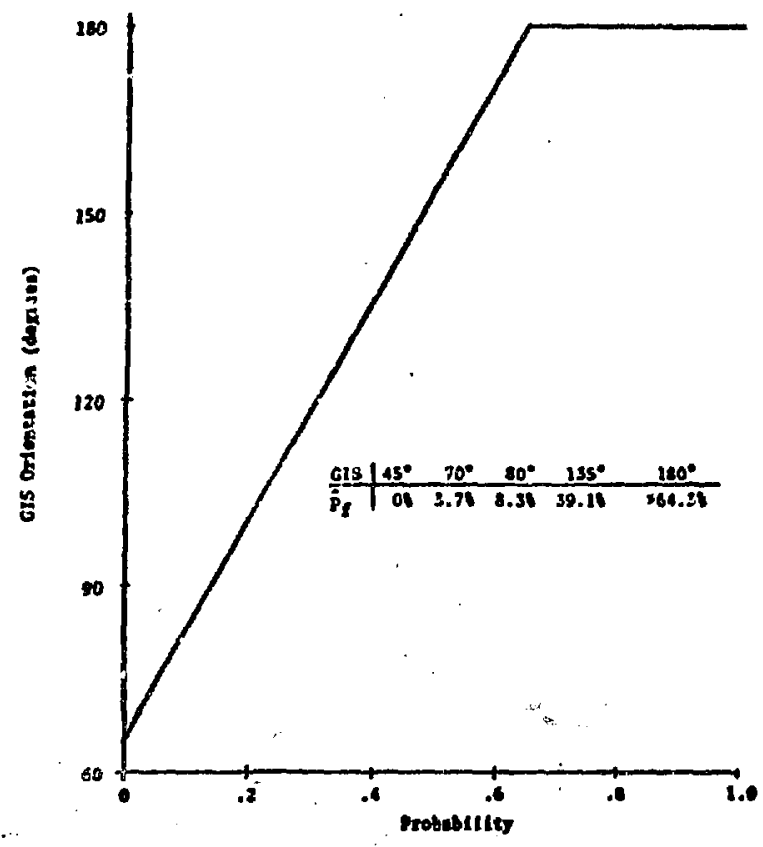

Fig. 2 .

Required test GIS orientation as a function of the desired probability that a fingerprint failure type does not occur. 
0.643 . The break-even GIS orientation for which there is a $50 / 50$ chance that a fingerprint failure type does not occur is seen to be $155^{\circ}$. The mean GIS orientation used in the 27 tests in Table $I$ is $166^{\circ}$, which corresponds to an estimated probability of $56 \%$ that a fingerprint failure type will not occur. This corresponds to the $56 \%$ observed proportion of test units that did not experience a fingerprint failure.

Finally, let us consider fuel failure types. Based on Eq. (13); Fig. 3 graphically provides the required test velocity and temperature combinations that are expected to yield a corresponding estimated probability $\hat{p}_{\text {fu }}$ that a fuel failure type does not occur. For example, if $\hat{p}_{f u}=0.8$ is desired, then one possible combination of temperature and velocity would be to test the unit at $1550^{\circ} \mathrm{C}$ and $86.65 \mathrm{~m} / \mathrm{s}$. Other combinations are, of course, feasible as well. Once the required test $t$ emperature has been selected in accordance with the desired hoop failure survivai probability (Fig. 1), this value may be used in Fig. 3 for determining the required test velocity. Recall that the break-even temperature was $1320^{\circ} \mathrm{C}$ from Fig. 1. Using this temperature, the break-even velocity is calculated from Eq. (13) at $86.26 \mathrm{~m} / \mathrm{s}$. Thus, the break-even test design variable values will use a temperature of $1320^{\circ} \mathrm{C}$, A GIS orientation of $155^{\circ}$, and a and a velocity of $86.26 \mathrm{~m} / \mathrm{s}$. At these values the test unit has an estimated 50/50 chance that each of the three failure types will be observed in the test unit. Let us now direct our attention toward future test plans. An important question concerns which test design levels should be selected in future MHW

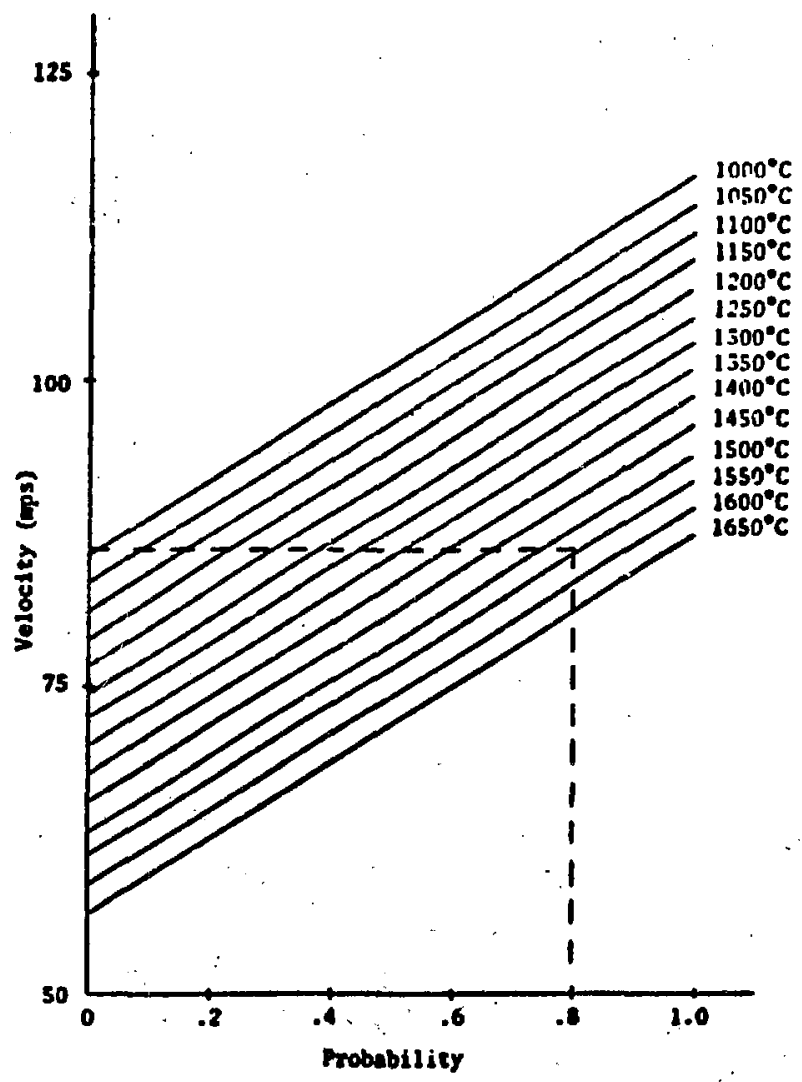

Fig. 3 .

Required test velocity and temperature as a function of the desired probability that a fuel failure type does not occur. 
tests. The entire testing program may be viewed as a sequential one-unit-at-atime procedure. Dixon and Mcod (1948) proposed a systela of staircase sampling for the estimation of the median (ur break-everi) effective dose based on juantal (success/failure) responses in biological assay problems. This staircase procedure will be modified for use here.

Consider the sequence of probabilities that a particular failure type does not occur, given by $5,10,25,50,75,90$, and 95 percent. Figure 4 outlines the testing program for successive future MHW units. This program is to be applied to each failure type separately; thus, the same probabilities will be used for all three failure types only at Step 1 and other steps for which all three failure types were simultaneously either present or absent. After three future units have been tested, the entire set of equations, such as Eqs. (11) - (13), should be updated (refitted) incorporating this new data. New figures corresponding to Figs. 1 - 3 should again be constructed. Once this has been done, Fig. 4 should again be used for the following three successive test units (future units 4 - 6). After the sixth future test unit, the same process wouid again be iterated, and so forth.

Table IV illustrates this cestinf procedure by a hypothetical scenario regarding the next three MHW test units, labeled sample number MHFT-60, MFT-61, and MHFT-62, respective1Y. By comparing Tables I and IV, it is observed that the most significant departure from sample numbers MHFT-55 through MHFT-59

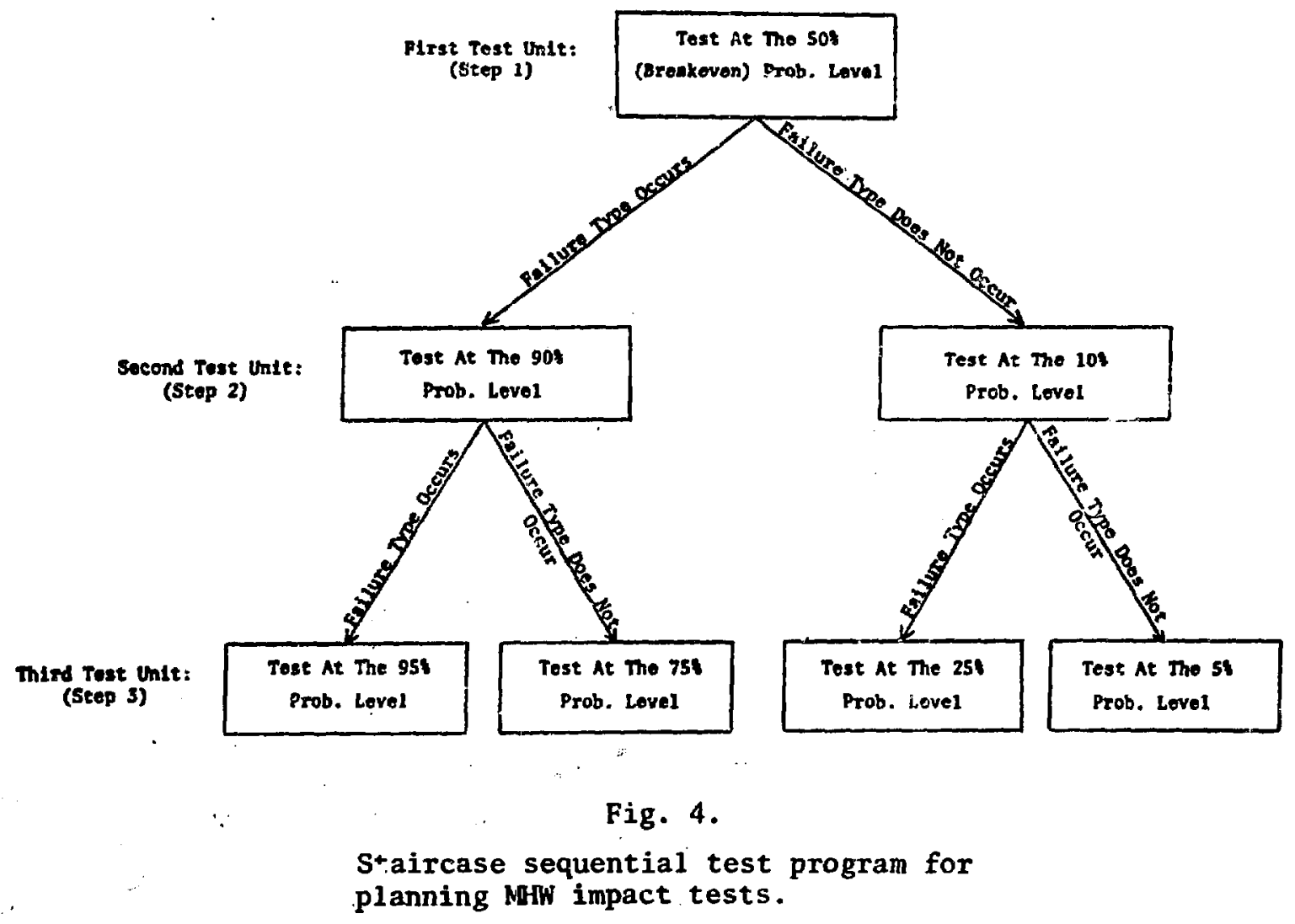




\begin{tabular}{|c|c|c|c|c|c|c|c|}
\hline \multirow[b]{2}{*}{$\begin{array}{c}\text { Sample } \\
\text { No. }\end{array}$} & \multicolumn{3}{|c|}{ Prob. Levels } & \multicolumn{3}{|c|}{ Test Design Variable Levels } & \multirow[b]{2}{*}{ Results } \\
\hline & $\hat{\mathrm{p}}_{\mathrm{h}}$ & $\hat{\mathrm{p}}_{\mathrm{f}}$ & $\hat{\mathrm{p}}_{\mathrm{fu}}$ & $\begin{array}{c}\text { Velocity } \\
(\mathrm{n} / \mathrm{s})\end{array}$ & Temp. & GIS Orientation & \\
\hline MHFT-60 & $50 \%$ & $50 \%$ & $50 \%$ & 86.3 & 1320 & $155^{\circ}$ & $\begin{array}{l}\text { Fing erprint Failure } \\
\text { Occurred }\end{array}$ \\
\hline MHFT-61 & $10 \%$ & $90 \%$ & $10 \%$ & 84.7 & 1070 & $180^{\circ}$ & $\begin{array}{l}\text { Fuel Failure Oc- } \\
\text { curred }\end{array}$ \\
\hline MHFT-62 & $5 \%$ & $75 \%$ & $25 \%$ & 90.5 & 1039 & $180^{\circ}$ & $\begin{array}{l}\text { Hoop Failure Oc- } \\
\text { curred }\end{array}$ \\
\hline
\end{tabular}

concerns the test temperature. Somewhat reduced test temperatures are indicated in the scenario of Table IV.

The main motivation for the staircase procedure considered here is that it directs attention at the region of test design values, which is expected to yield valuable data for fitting reliable curves, such as Eqs, (11) - (13). The procedure strives toward the critical levels of the test design variables at which the failure types are manifested. However, if a sequence of probability values other than that suggested here is desired, this new sequence may be used in the same basic staircase procedure described here.

\section{v. CONCLUSIONS}

First, let us summarize this report. The results of $27 \mathrm{MHW}$ impact tests were statistically analyzed by use of zero-one weighted linear regression analysis. The resulting equations clearly established the following facts. Test temperature significantly affects the incidence of hoop failure. As test temperature increases, the likelihood of hoop failure decreases. Also, the GIS orientation significantly affects the incidence of fingerprint failure. As GIS orientation increases, the likelihood of fingerprint failure also decreases. Finally, both test temperature and velocity affect the incidence of fuel failure. As these both increase, the likelihood of fuel failure likewise decreases.

These results were used to develop a procedure for planning and conducting future MHW tests. A staircase method was developed for tise with successive sets of three MHW test units. The staircase method directs the test variables toward those critical levels which excite the failure modes. The results of each successive test are used in determining the levels for the succeeding test. After three tests are completed, the entire statistical analysis must be updated to incorporate these test results. The three-unit testing program is then repeated.

The analysis and test planning procedure developed here is a general one and its use is not restricted to the MHW program. A similar testing program can be developed along these same lines for any other test program in which the presence or absence of a failure mode is observed, based on known values of test conditions. Al1. of the analysis may be easily accomplished by means of existing welldocumented computer codes, particularly by use of BMDPZR-Stepwise Regression in the BMDP Statistical Library. This code is available at LASL. 
There are several advantages in the use of a statistical approach over a nonstatistical approach: The main advantage lies in the fact that equations such as Eqs. (11) - (13) can be us (ad to set probabilistic design limits and goals as those critical levels of the design variables that have a high probability of being met. For example, the unit may be required to be designed to be free from failure upon impact at $X \mathrm{~m} / \mathrm{s}$ with $Y \&$ probabilit:. In this case, Eqs. (11)-(13) can be fitted to the test data for use in determining whether or not this requirement has been met. Secondly, the statistical approach represents a convenient way to explore the test data to determine which design variables excite which failure modes." This information may be used in redesign efforts to reduce the incidence of failure. For example, knowledge of the fact that hoop failure. type is infl'renced by temperature is important in designing the unit to ensure temperature conformance. Finally, the statistical approach permits conformance to design limits to be verified as either having been met or not. 'For example, if stimated probabilities from Eqs. (11) - (13) are sufficientiy high for worst ca. :........ Sons, then it may be clained that the RTG FSA's have been demonstrated to confoim to design goals. Advantages such as these are not present within current testing procedures in which statistical analysis is not performed.

The testing procedure described here is not appropriate in new testing prograins for which test results are not yet available. In a case such as this, either of the following two procedures should be followed in planning the testing. First, suppose that the new units are similar in design to the MH units. In this case, equations such as Eqs. (11) - (13) can be "bootstrapped" for use at the outset of the new program prior to the attainment of actual test results. The first test unit will be tested at the 1 eak-even levels of the ve-sign variables. The second and third tinits should be tested at the $90 \%$ and $10 \%$ probability leve1s, respectivtly. Orce these three test results are known, zero-one weighted linear regression equations can be fitted to these data, and the procedure outlined in Fig. 4 followed for the next three units.

Second, suppose that the new test units are considered to be significantly difierent from previous units in such a way that existing equations, such as Eqs. (11) - (13), cannot be used at the outset. In this case, the following procedure is recommended. Based on the design values of the test design variables, identify the maximum spread for each of the design variables. For convenience, let us assume that tr esign variables of interest are again temcerature, velocity, and GIS $\sigma^{\circ}$ tation. The first eight test units should be conducted according to the $d, n$ given in Table $V$, where "MIN" and "MAX" are used to denote the limits of ..e corresponding test design variable for that unit. If possible, the MIN and MAX values should remain unchanged for the entire sequence of eight tests; however, this is not strictly required. Once the eight tests have been completed, the results should be used in constructing suitable zero-one weighted linear regression equations, as described and illustrated in Section III. Remaining tests, beginning with the ninth, should then follow Fig. 4 and the procedure presented here. It is noted that the test design levels in Table $v$ form the vertices of a cube and are quite efficient for fitting the required linear regression models. 


\section{TABLE V}

DE:SIGN VARIABLE LEVELS FOR THE FIRST EIGHT

TESTS IN A NEW IMPACT TEST PROGRAM

\begin{tabular}{|c|c|c|c|}
\hline Test Sequence No. & Temperature & Velocity & GIS Orientation \\
\hline 1 & MIN & MIN & MIN \\
\hline 2 & MAX & MIN & MIN \\
\hline 3 & MIN & MAX & MIN \\
\hline 4 & MIN & $M_{1}{ }^{7}$ & MAX \\
\hline 5 & MIN & MAX & MAX \\
\hline 6 & MAX & MIN & MAX \\
\hline 7 & MAX & MAX & MIN \\
\hline 8 & MAX & MAX & $\operatorname{MAX}$ \\
\hline
\end{tabular}

\section{REFERENCES}

1. Cramer, E. M., "Performance of Multihundred-Watt Fueled Sphere Assemblies in. the Safe:" Sequential Test Program," Los Alam 3 Scientific Laboratory report LA-5916 (July 19\%5).

2. Cramer, E. M., "Performance of Multihundred-Watt Fueled Sphere Assemblies in the Safety Verification Test," Los Alamos Scientific Laboratory report LA6082 (January 1976).

3. Dixon, W. J. and Mood, A. M., "A Method for Obtaining and Analyzing Sensitivity Data," Journal of the American Statistical Association, Vo1. 43, (1948) pp. 109-126.

4. Finney, D. J., Statistical Method in Biological Assay. (New York: Hafner Publishing (o., 1952).

5. Neter, J. and Wasserman, W., Applied Linear Statist cal Models. (Homewood, IL: Richard. D. Irwin, Inc., 1974). 